\title{
TRABAJ0, MOVILIDAD Y HUELLA: APUNTES SOBRE EL IMPACTO ECOLÓGICO DEL ARTE CONTEMPORÁNEO
}

\author{
Esmeralda Gómez Galera \\ Universidad de Castilla la Mancha. Doctoranda
}

\section{Resumen}

El artículo plantea una pregunta sobre el impacto medioambiental del arte contemporáneo como sector profesional. Para ello establece una relación entre dicho sector y un creciente nomadismo en el circuito artístico global. Posteriormente reflexiona sobre los flujos, desplazamientos aéreos que trazan líneas en el mapa del arte contemporáneo, y sobre la condensación de estos flujos, analizando el caso de las ferias de arte. Por último, se mencionan algunas estrategias que pueden ayudar a reducir la huella ecológica y se imagina la posibilidad de otras movilidades más sostenibles.

\section{Palabras clave: ARTE CONTEMPORÁNEO; TRABAJO; NOMADISMO; MOVILIDAD; HUELLA ECOLÓGICA}

\section{WORK, MOBILITY AND FOOTPRINT: NOTES ON THE ENVIRONMENTAL IMPACT OF CONTEMPORARY ART}

\section{Abstract}

This article raises a question about the environmental impact of contemporary art as a professional sector. To this end, it establishes a relationship between this sector and a growing nomadism in the global art circuit. Subsequently, it reflects on the flows, aerial displacements that draw lines on the map of contemporary art, and on the condensation of these flows, analysing the case of art fairs. Finally, it mentions some strategies that can help reduce the ecological footprint and imagines the possibility of new, more sustainable mobilities.

Keywords: CONTEMPORARY ART; WORK; NOMADISM; MOBILITY; ENVIRONMENTAL FOOTPRINT

\footnotetext{
Gómez Galera, Esmeralda. 2019. "Trabajo, movilidad y huella: Apuntes sobre el impacto ecológico del arte contemporáneo“. AusArt 7 (2): 77-89. DOI: 10.1387/ausart.21148
}

\section{AUSART}




\section{EL NOMADISMO COMO COMPLEMENTO DEL TRABAJO (ARTÍSTICO)}

En las últimas décadas se teorizó sobre el nomadismo con cierta fascinación. El concepto estuvo presente en las ideas arquitectónicas de Constant, el pensamiento de Deleuze y Guattari o, más recientemente, en las reflexiones del filósofo español Francisco Jarauta. Como construcción conceptual, el nomadismo contenía la promesa de una experiencia de libertad y era en sí mismo un ideal emancipatorio que parecía poder desembarazarnos de las viejas imágenes de pensamiento y convenciones sociales establecidas. La sensibilidad postmoderna fue nómada de alguna manera, en tanto prestó más atención a las ideas de inmanencia y devenir que a los grandes ejercicios de fundamentación. Constant Nieuwenhuys describió su Nueva Babilonia como "un alojamiento temporal, constantemente remodelado; un campamento para nómadas a escala planetaria" (Nieuwenhuys 2009). El nómada habitante de esta ciudad sería un ser creativo y libre para el juego, entregado a la construcción de situaciones y sin una vivienda fija. No obstante, en lugar de responder al juego, la creatividad, el devenir y la experimentación constantes como quería el arquitecto holandés, la experiencia contemporánea del nomadismo parece responder a las exigencias del capital en un mercado de trabajo precario, globalizado y mediado tecnológicamente. De modo que se asemeja más a una promesa hecha añicos que a un concepto con potencial emancipador. La institución del trabajo ha conquistado su ubicuidad gracias a la mediación de las, ya no tan nuevas pero siempre obsolescentes, tecnologías, especialmente en un contexto globalizado en el cual las distancias se acortan mientras las brechas crecen y en un sector artístico, que es el tema que nos ocupa, precario y desregulado.

Resulta paradójica la autopercepción que de sí mismo tiene en ocasiones dicho sector, como si la precariedad y la movilidad constantes que lo caracterizan fueran un valor positivo. Así, el mundo del arte es definido como una "comunidad compleja, vaporosa y nómada" (Garutti 2014) mientras que la vida de los comisarios independientes es descrita con la contradictoria fórmula de precaria y glamurosa (Indrisek 2018). La fotografía de una comisaria recién llegada a Venecia con sus maletas a cuestas resume visualmente esa contradicción, y es que las imágenes también ayudan a construir esta narrativa en un contexto de sobreexposición en redes sociales. El nómada del sector artístico se desplaza constantemente con el trabajo a cuestas, una roca de Sísifo que cabe en un equipaje sin facturar en el aeropuerto. Según Graciela Speranza, que ha teorizado sobre el arte portátil y la "errancia voluntaria" en la postmo- 
dernidad, "la globalización ha abierto y acelerado la circulación cultural, pero a distintas velocidades según las rutas y la dirección de los intercambios económicos. Y aunque las teorías culturales poscoloniales han promovido la ampliación del mapa global para incluir a las culturas periféricas, el multiculturalismo institucionalizado fetichiza al otro de los márgenes sin alterar las estructuras de los poderes centrales" (Speranza 2012). Los destinos están bien definidos en el circuito artístico global y toman la forma de las principales bienales y ferias de arte contemporáneo.

¿Cuál es el impacto medioambiental de esta creciente errancia? Se trata de una pregunta incómoda que merece la pena plantear en un escenario de crisis ecológica como el actual, sobre todo cuando tantos análisis sobre el tema de la precariedad y movilidad en el sector del arte contemporáneo se centran más en los efectos que estas tienen sobre los propios agentes artísticos que sobre su entorno, un entorno no inmediato pero del que no es posible sustraernos. La intención de estos apuntes es reflexionar sobre la huella ecológica de nuestro sector profesional, caracterizado por la movilidad constante de bienes y personas. Para ello me detendré primero en los flujos, desplazamientos aéreos que trazan líneas en el mapa del arte contemporáneo y posteriormente en la condensación de estos flujos, analizando el caso de las ferias de arte. Por último, menciono algunas estrategias que pueden ayudar a reducir la huella ecológica de la industria del arte e imagino la posibilidad de nuevas movilidades más sostenibles a partir del trabajo de la artista suiza Marinka Limat. Reparar en el impacto ecológico de nuestra actividad profesional es una cuestión que rebasa los límites de dicha actividad y solo puede hacerse apelando a una responsabilidad ecológica, que es también una responsabilidad ética.

\section{FLUJOS: LÍNEAS EN EL AIRE}

Buena parte del desplazamiento en el sector artístico toma la forma de vuelos hacia los principales aeropuertos del circuito del arte globalizado: grandes museos, ferias de arte contemporáneo, bienales, etc. La expresión "estar en el aire" describe precisamente una situación de inseguridad e inestabilidad y en un sector laboral "vaporoso" que apela a la movilidad constante es pertinente detenerse a pensar sobre el espacio del avión como intervalo. 
Desde hace años cada vez que subo a un avión hago un dibujo durante el despegue y otro durante el aterrizaje. Comenzó en el aeropuerto de Madrid con un método estricto: postura corporal y respiración consciente, cuaderno sobre las rodillas, bolígrafo de tinta negra en la mano derecha, ojos cerrados, atención puesta en el instante... pero con un alto grado de indeterminación y aleatoriedad en el dibujo: dejarse llevar por el proceso y afectar por el movimiento, registrando en el papel los giros, la vibración y los pequeños zarandeos del avión justo en el momento de dejar o tocar tierra. Desde la articulación del hombro hasta los dedos de la mano, el brazo se transforma en una extensión del cuerpo similar a la aguja de un sismógrafo, deslizándose por la superficie del papel mientras registra líneas quebradizas. Alimentándose del tiempo y la constancia, "Plane Drawings" (2015-act.) se ha convertido en un archivo sistemático de los propios desplazamientos y la propia huella. Los vuelos se repiten con frecuencia hacia un mismo lugar cuando trabajaba en un proyecto expositivo y en ocasiones los dibujos resultantes se han mostrado también como parte del mismo, una parte que permanecería invisible de otro modo, dando la apariencia de que la exposición emerge en la sala en lugar de ser fruto de un diálogo sostenido y una serie de desplazamientos que lo hacen posible.

Entre los dos dibujos, despegue y aterrizaje, se habita un espacio imposible de habitar realmente, un no-lugar (Auge 1992) ideado para el tránsito y en el que no es posible sensación de pertenencia alguna. Se trata de un intervalo en el que, según Michel Onfray

impera una lógica especial: ya no en el lugar que se ha dejado, todavía no en el lugar pretendido. (...) Ese lugar de extraterritorialidad no parece gobernado por lengua alguna, ni por ningún tiempo. ¿Qué idioma hablar, por ejemplo, cuando estamos en el avión? ¿El del país que deja o el del país de destino? ¿en qué lugar viajamos una vez confinados en el aire? ¿El de la ley que supone el espacio aéreo propiedad del país sobrevolado? ¿Qué punto del cielo permite afirmar rotundamente que se ha franqueado una frontera?

(2016)

El intervalo se caracteriza entonces por su indeterminación, es un espacio indefinido en el cual se suspenden momentáneamente las convenciones sociales y temporales. En el "entre" que supone el vuelo no existe una relación sencilla con los husos horarios ni con los caprichos de la geopolítica. Lingüísticamente, el inglés se impone en el intervalo, aunque se trata de un inglés de límites blandos, maleables por los diversos acentos y lugares de procedencia de las personas que lo hablan. En el avión y en sus esperas puede llegar a 
generarse una comunidad circunstancial a la que nadie pertenece verdaderamente y que no tiene demasiada razón de existir más allá del pasajero confinamiento, por ello nace en el aeropuerto de salida y se disuelve en el de llegada. No obstante, el intervalo puede ensancharse gracias a la producción de sentido y en ocasiones la práctica artística es capaz de dotar de contenido a ese paréntesis de indeterminación que es el vuelo. Dos ejemplos significativos son las pinturas aeropostales del artista chileno Eugenio Dittborn y el proyecto de Francis Alÿs "The Loop" que representan dos tipos de flujos aéreos en el mapa del arte contemporáneo: el primero correspondería al transporte de obra y el segundo a la movilidad de los propios agentes artísticos.

Como apuntaba Onfray, durante el vuelo se cruzan fronteras que pasan completamente inadvertidas para los pasajeros, pero en el acceso al mismo suelen desplegar su violencia burocratizada, sus restricciones y prohibiciones. Fue precisamente durante la dictadura de Pinochet cuando el chileno Eugenio Dittborn comenzó a trabajar en sus pinturas aeropostales. Se trata de trabajos bidimensionales que pliega cuidadosamente o introduce por secciones en un sobre que luego es enviado por correo postal aéreo. A pesar de su mediano tamaño, estos sobres, siempre expuestos junto a las pinturas desplegadas, son contenedores de un amplio espacio conceptual y geográfico. En un breve ensayo con ocasión de la última exposición del artista en la galería Alexander and Bonin, Laura Braverman realiza una observación interesante cuando repara en el hecho de que a menudo las rutas aéreas de estas pinturas "han sido representadas en los catálogos del artista como líneas que atraviesan la superficie de la Tierra" (Braverman 2018). El recorrido de las pinturas aeropostales es acumulativo, en tanto el itinerario está definido por su exposición en galerías, museos e instituciones de diferentes países. Un ejemplo es la pintura aeropostal No.70 que ha pasado por ciudades tan distantes como Londres, Berlín, Rotterdam, Boston, Santiago... Dittborn lleva la cuenta de esta circulación constante que, "en el mapa del mundo" es "como una escritura a escala gigantesca” (Braverman 2018). La relación de las pinturas aeropostales con la escritura es doble. Por un lado, en su desplazamiento a gran escala actúan como trazos-líneas en el cielo, por otro, la palabra escrita también está presente en los sobres enviados por el artista. En muchos casos se trata de una escritura enigmática, que intenta desentrañar el proceso que conduce a la pintura aeropostal, alude a su contenido simbólico, la itinerancia o la elástica relación entre el destinatario y el remitente. Estos trabajos de Dittborn difuminan el dualismo entre pintura y escritura, contenido y continente, en el momento en que el sobre es expuesto junto a la pintura como un conjunto indiscernible que disputa la mirada. 

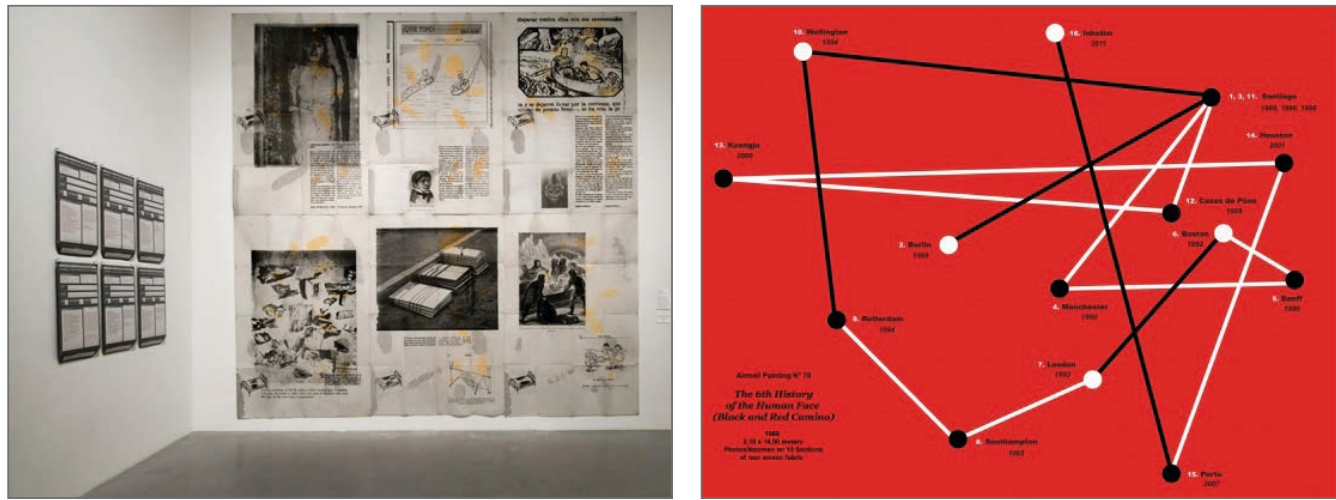

1. Eugenio Dittborn, To Return (RTM) Airmail Painting No.103, 1993.

Itinerary of airmail painting No. 70,The 6th History of the Human Face (Black and Red Camino), 1989

Por otra parte, el proyecto de Francis Alÿs en "The Loop" traza también unas líneas que es posible seguir para reconstruir el desplazamiento del artista. En 1997 fue invitado a participar en la muestra internacional InSITE que ponía el foco en el contexto de la región fronteriza San Diego-Tijuana. Evitando cruzar la frontera entre México y Estados Unidos, cuya conflictividad no ha hecho más que aumentar en los últimos años, Alÿs emprende un viaje de 29 días y 16 ciudades, registrando las escalas y fechas del mismo en un mapa en formato postal. Como una hoja de ruta que combina de nuevo escritura e imagen, el artista describe los movimientos a realizar: "tomaré una ruta perpendicular a la banda divisoria. Desplazándome $67^{\circ} \mathrm{SE}$, luego hacia el NE y de nuevo hacia el SE, circunnavegaré la Tierra hasta llegar al punto de partida. Los objetos generados por el viaje darán fe de la realización del proyecto, que quedará libre de cualquier contenido crítico más allá del desplazamiento físico del artista"2. De este modo, Alÿs invierte el presupuesto de la exposición en un viaje en avión de Tijuana a Ciudad de México, pasando luego por Panamá, Santiago, Auckland, Sídney, Singapur, Bangkok, Rangún, Hong Kong, Shanghái, Seúl, Anchorage, Vancouver y Los Ángeles para finalmente aterrizar en San Diego, no demasiado lejos del punto de partida. Con este impresionante cambio de escala en la propia concepción del viaje pone en marcha una manera, indiscutiblemente privilegiada, de burlar el paso fronterizo. Invirtiendo una gran cantidad de esfuerzo para lograr un mínimo resultado, "The Loop" evidencia una comprensión de la complejidad de lo liminar como frontera geográfica pero también política. Así mismo, según Graciela Speranza este torbellino de movilidad al que Alÿs se somete podría interpretarse como "una ironía sobre el turismo del viajar sin ver y la superficialidad mundana de la vida del artista globalizado" (2012). 


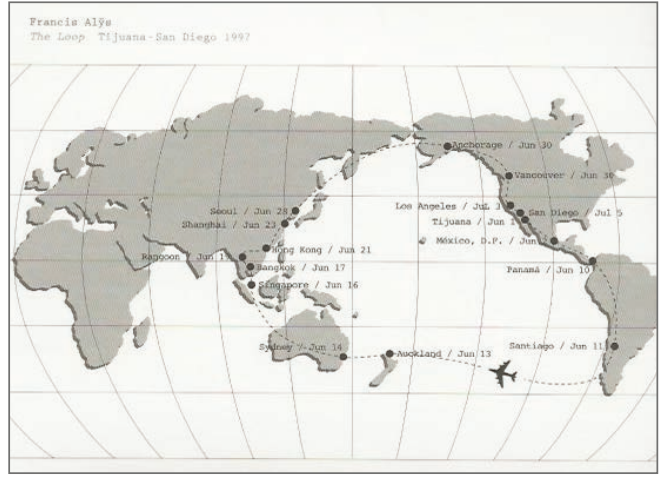

2. Francis Alÿs, The Loop 1997.

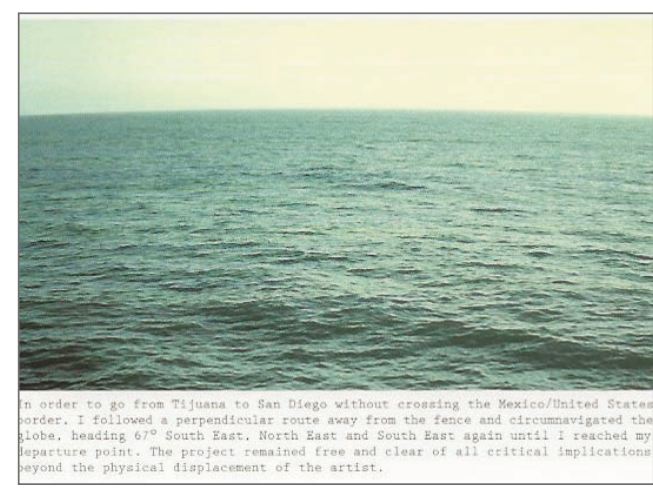

Las rutas emprendidas por las pinturas de Eugenio Dittborn y por Francis Alÿs parecen ser diametralmente opuestas. En el primer caso lo que viaja son las pinturas aeropostales que construyen acumulativamente su propio itinerario mientras la presencia del artista se convierte en algo prescindible, en tanto la pintura y la escritura actúan como huellas de dicha presencia. En el extremo opuesto, Alÿs no solo se aventura personalmente al viaje, sino que lo hace a modo de hipérbole, realizando sistemáticamente el trayecto más largo y aparentemente absurdo, rodeando el océano pacífico en una conexión de vuelos internacionales. No obstante, ambas son una representación de los flujos aéreos en el arte contemporáneo que toman forma fundamentalmente de transporte de obra y desplazamiento de personas. Es complejo determinar la densidad de dichos flujos. Por ejemplo, si tomamos el caso de una exposición colectiva con obra de artistas internacionales en una galería, tendrá lugar el transporte de las piezas desde diferentes lugares del mundo para reunirse en el espacio expositivo; o el de un evento a gran escala, que requiere la presencia de numerosos profesionales del mundo del arte. En ocasiones los flujos se concentran hasta generar condensaciones, como es el caso de las ferias de arte contemporáneo analizado en el próximo apartado.

\section{CONDENSACIONES: EL CASO DE LAS FERIAS DE ARTE CONTEMPORÁNEO}

El pasado mes de junio en Art Basel's Conversations, un panel de discusiones con gran amplitud temática programado por Julieta Aranda, tuvo lugar un 
interesante, quizá por inusual, debate en torno a la huella ecológica del arte contemporáneo. Se trata de un sector profesional que, como cualquier otro en este momento crítico, tiene la responsabilidad de dirigir la mirada hacia sus propias prácticas y hacia el problema de la crisis medioambiental, hacer autocrítica con respecto a su contribución al mismo y reflexionar sobre las posibles estrategias que permitan reducir su impacto, esto es, imaginar colectivamente modos de hacer más sostenibles desde el punto de vista ecológico. Los panelistas abordaron el debate desde trayectorias profesionales diversas y una preocupación común, mostrando acuerdo en que la principal contribución al problema es la de la movilidad de los propios agentes que participan del circuito del arte, entendiendo estos en un sentido amplio. Por un lado, la movilidad de los profesionales: artistas, comisarios, galeristas, representantes de instituciones o colecciones, etc. por otro, la de las audiencias especializadas y el público que en ocasiones se desplaza exclusivamente con el propósito de asistir a un evento o visitar una exposición. Sin duda los picos de movilidad se alcanzan en grandes encuentros como son las bienales y ferias de arte contemporáneo. Además, recientemente se ha producido un auténtico boom de las mismas para dar cabida a una supuesta diversidad del mercado, una creciente producción artística y a las propuestas de galerías jóvenes que no tienen acceso a las ferias más establecidas en el circuito del arte. Estas últimas juegan a relocalizarse en nuevos escenarios (Basel Miami Beach, Basel Hong Kong) mientras aparecen pequeñas ferias que suelen pivotar en torno a una principal para así poder nutrirse en términos de visibilidad y económicos de la movilización masiva motivada por aquellas. Nos guste o no, constituyen una parte importante del panorama del arte contemporáneo y lo hacen a escala internacional en un momento en el cual las compañías aéreas 'low cost' cubren grandes distancias por precios irrisorios y han ganado una enorme popularidad.

En las últimas décadas las ferias "se han convertido en eventos capaces de aglutinar múltiples aspectos del mundo del arte contemporáneo y, en muchos casos, proporcionan una instantánea de su complejidad en una forma resumida que no es fácil de conseguir en otros entornos institucionales" (De Bellis 2014). De este modo, su principal función sería la de ser una especie de "recipiente que acoja un amplio abanico de situaciones, estructuras y experiencias, un punto de encuentro en el que diferentes figuras profesionales relacionadas con el arte contemporáneo, así como otros ámbitos, pueden entrar en contacto e intercambiar ideas" (ibíd.). Ahora bien, este punto de encuentro y esta manera de entrar en contacto (come together en el original) implica necesariamente un desplazamiento masivo de personas y recursos. Por tanto, la instantánea compleja que en teoría proporcionan las ferias nos deja apreciar 
también de una forma condensada el impacto medioambiental del arte contemporáneo. A las movilidades mencionadas anteriormente, profesionales y audiencias, habría que añadir también el propio transporte de las obras de arte en relación al cual cabe mencionar otro punto delicado que es el de los embalajes de un solo uso: las montañas efímeras de plástico de burbujas aparecen durante los días de montaje en los pasillos de un pabellón de feria y desaparecen mágicamente durante la limpieza nocturna previa a la apertura, de modo que la imagen ofrecida a los visitantes será reluciente. Ya que la ideología del cubo blanco (O'Doherty 1981) nos conduce constantemente a estrategias de ocultación que aíslan al espacio expositivo de su realidad social, económica y ecológica, es importante que al menos tengan lugar conversaciones centradas específicamente en este tema para poner sobre la mesa la cuestión de la responsabilidad ecológica y hacer autocrítica.

\section{PUNTOS DE ENCUENTRO MÁS SOSTENIBLES}

Analizado el tema de la movilidad y la huella ecológica en el arte contemporáneo cuyo mayor ejemplo, por la condensación que operan en el tiempo y el espacio, serían las ferias de arte, cabe preguntarse qué se puede hacer al respecto. ¿Qué estrategias son las que permitirían reducir su impacto? Las respuestas son variadas y existen muchas líneas de actuación posibles que dependen fundamentalmente del rol que desempeñamos en estos puntos de encuentro, pero me gustaría al menos mencionar algunas ideas que son sencillas de implementar. Con respecto al transporte de obra, dos estrategias son trabajar con embalajes sostenibles reutilizables y evitar el transporte aéreo. Esta última requiere una mayor planificación por parte de las galerías para explorar formas alternativas de transporte que normalmente ofrecen menos frecuencia, flexibilidad y rapidez, pero cuya huella de carbono es notablemente inferior. Además, una acción complementaria es la que llama a la colaboración con otras galerías locales participando en las mismas ferias, en cuyo caso se pueden organizar transportes de manera conjunta para reducir emisiones. Por ejemplo, en el caso de un transporte marítimo con seis cajas de madera de grandes dimensiones el impacto medioambiental es significativamente menor al de dos envíos aéreos de tres cajas cada uno. Esta posibilidad de colaboración requiere, por una parte, extender la concienciación del problema medioambiental en el sector artístico y, por otro, deponer un enfoque competitivo en favor de uno cooperativo. Las posibles estrategias en cuanto 
a la movilidad de personas no son muy diferentes pero dependen en mayor medida de las propias circunstancias y el papel de cada cual en estos eventos. Si bien es fácil calcular las emisiones de un transporte aéreo o un transporte marítimo para el mismo envío, no hay una fórmula que permita deducir matemáticamente si el desplazamiento merece la pena o no. Esto implica sopesar, en una economía de la experiencia, ¿cuál es la disposición de cada cual a renunciar al privilegio de ciertas experiencias por el impacto medioambiental de las mismas? Tras este cuestionamiento es posible planificar con tiempo y valorar la sostenibilidad de diferentes opciones de transporte. Otra estrategia que las galerías pueden implementar sería la de trabajar lo máximo posible con proveedores en el contexto local de la feria en lugar de movilizar al propio equipo de montaje, técnicos, fotografía, etc.

Por último, siempre existe la posibilidad de implementar acciones paralelas de compensación de carbono, que consiste en una reducción de la emisión de carbono planificada para mitigar los efectos de la emisión efectuada en otro lugar o actividad, por ejemplo, en un desplazamiento. Esto puede hacerse de manera individual o a través de proyectos de compensación de carbono en
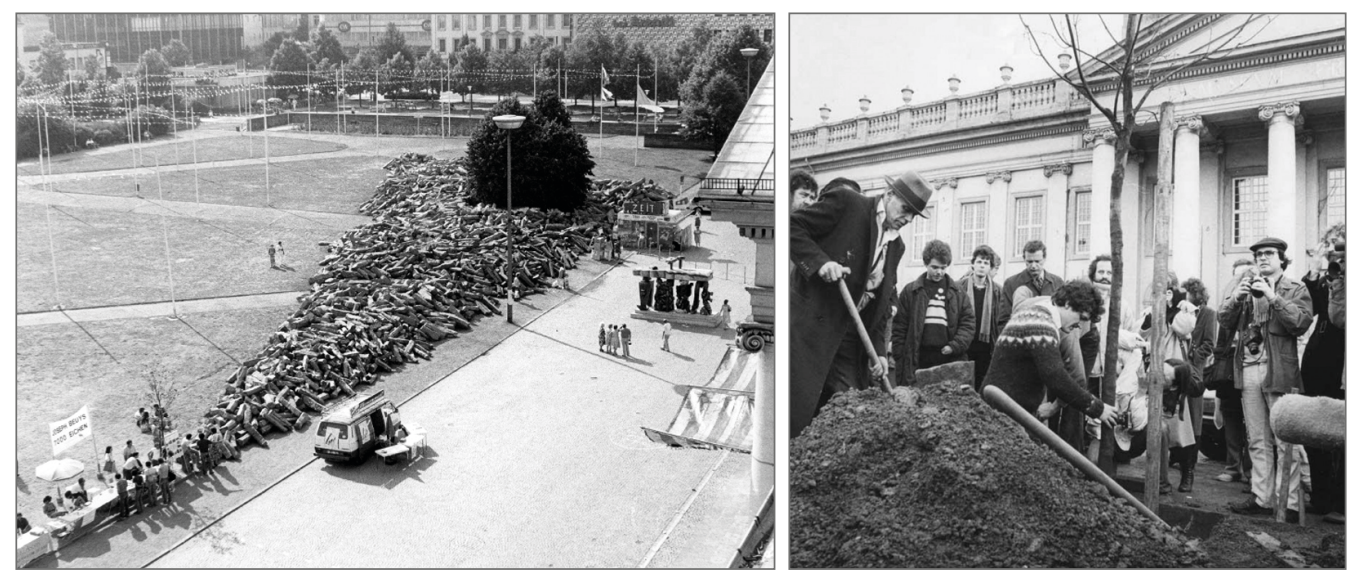

3. Joseph Beuys 7.000 Oaks, 1982.

los que es posible colaborar. Además, las acciones paralelas también podrían llegar a formar parte del propio programa de una feria o evento de arte contemporáneo. Ejemplo paradigmático de una acción artística que resulta en una compensación de carbono en el contexto de un gran evento artístico es el proyecto "7.000 Oaks" de Joseph Beuys. En la Documenta7 (1982) el artista plantó 7.000 árboles que cambiaron el aspecto visual de la ciudad y por otra parte tuvieron el efecto de equilibrar el posible impacto ecológico. Mediante 
sencillas estrategias como las mencionadas, ¿seremos capaces de generar puntos de encuentro más sostenibles?

\subsection{Otras movilidades}

Establecido el hecho de que el desplazamiento parece condición de posibilidad para condensarnos momentáneamente en un punto de encuentro y por tanto resulta esencial en el paisaje del arte contemporáneo, no me gustaría cerrar estos apuntes sin mencionar la posibilidad de imaginar otras movilidades. En 2017, treinta y cinco años después del proyecto de Beuys, tuvo lugar la Documenta14. La artista suiza Marinka Limat partió de la ciudad alemana para caminar hasta Atenas, que fue la segunda sede de esta última edición. Emprendía la caminata como una peregrina del arte contemporáneo, deteniéndose en diversos museos e instituciones en el camino para ser bendecida en el nombre del arte y continuar con su viaje. Se trata de una peregrinación de 163 días a pie, recorriendo 2.500 km y nueve países: Alemania, República Checha, Austria, Eslovaquia, Hungría, Servia, Kosovo, Macedonia y Grecia.
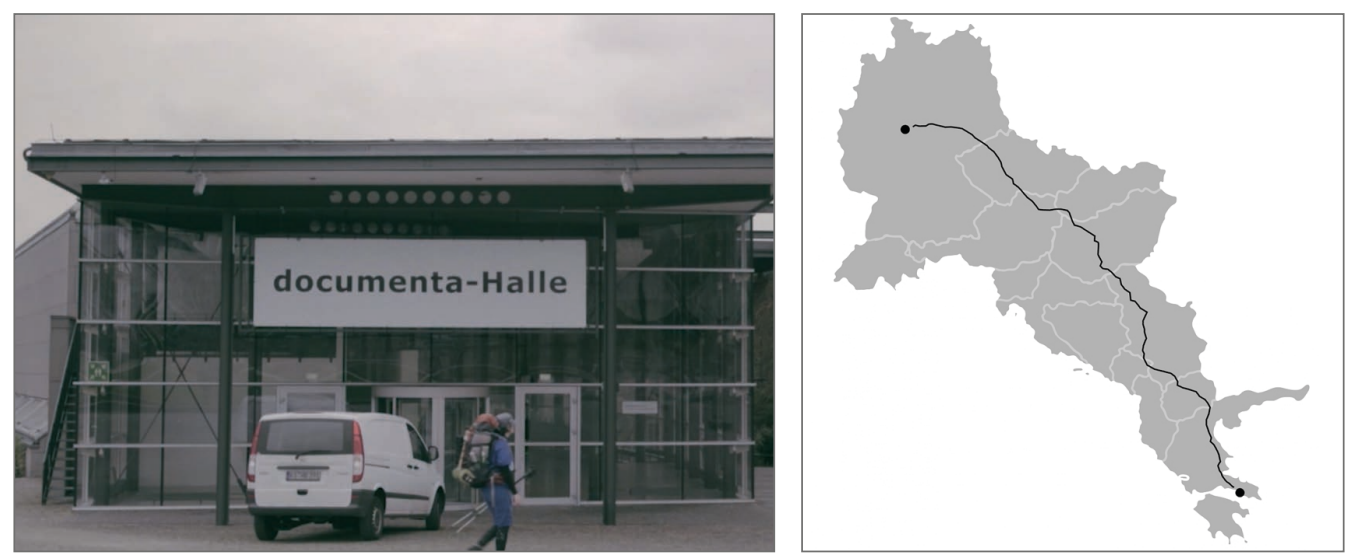

4. Marinka Limat Kunstpilgerreise 3, 2017.

Al igual que el loop aéreo de Francis Alÿs, el peregrinaje de Limat trata del viaje como hipérbole de la movilidad: cubriendo grandes distancias y atravesando múltiples fronteras; pero al modelo insostenible del artista globalizado y deslocalizado, Limat contrapone el del peregrino artístico. Así, se pregunta por el poder de atracción, casi religioso, de las grandes mecas del arte contemporáneo pero lo hace humanizando las distancias, otorgándoles su tiempo, y estableciendo una relación directa con los lugares por los que transita. En 
torno a $5 \mathrm{~km} / \mathrm{h}$ es el ritmo normal del caminar, un ritmo que según Rebeca Solnit permite un estado "en el cual la mente, el cuerpo y el mundo están alineados, como si fueran tres personajes que por fin logran mantener una conversación, tres notas que de pronto alcanzan un acorde" (Solnit 2015) El peregrinaje a Atenas es el tercero de una serie inacabada, también el más ambicioso proyecto emprendido por la artista hasta el momento. En él Limat plantea con ironía la posibilidad de nuevas (por muy antiguas en realidad) movilidades sostenibles con nuestro entorno. Con sus propios pies la artista opera una desaceleración y traza líneas de forma distinta en el globalizado e interconectado mapa del arte contemporáneo para posibilitar en él esas condensaciones que son necesarias como punto de encuentro pero no necesariamente han de ser destructivas o insostenibles desde un punto de vista ecológico.

\section{Referencias bibliografícas}

Augé, Marc. (1992) 2000. Los no lugares: Espacios del anonimato; Una antropología de la sobremodernidad. Traducción, Margarita N. Mizraji. Barcelona: Gedisa

Braverman, Laura. 2018. "Primordial Marks". En Pinturas aeropoestales recientes: May 5-June 23, Eugenio Dittborn. New York: Alexander and Bonnin. https://issuu.com/alexanderandbonin/docs/ed_brochure_pdf

De Bellis, Vicenzo. 2014. "Prologue". En Fairland: Explorations, insights and outlooks on the future of art fairs, edited by Francesco Garutti, text by Stefano Baia Curioni et al. London: Koenig

Deleuze, Giles \& Félix Guattari. (1980) 2004. Mil mesetas: Capitalismo y esquizofrenia. Traducción de José Vázquez Pérez, con la colaboración de Umbelina Larraceleta. Valencia: Pre-textos

Fernández Vicente, Antonio, coord. 2010. Nomadismos contemporáneos: Formas tecnoculturales de la globalización. Murcia: Universidad de Murcia

Indrisek, Scott. 2018. "The precarious, glamorous lives of independent curators". Artsy, 8 feb. www.artsy.net/article/artsy-editorial-precarious-glamorous-lives-independent-curators

Limat, Marinka. 2017. "Kunst-Pilger-Reise". Web del proyecto. http://kunstpilgerreise.ch

Nieuwenhuys, Constant Anton. 2009. La nueva Babilonia. Traducción, Maurici Pla. Barcelona: Gustavo Gili

O’Doherty, Brian. (1981) 2011. Dentro del cubo blanco: La ideología del espacio expositivo. Traducción, Lena Peñate Spicer Murcia: Cendeac

Onfray, Michel. 2016. Teoría del viaje: Poética de la geografía. Traducción de Juan Ramón Azaola. Barcelona: Taurus

Solnit, Rebecca. 2015. Wanderlust: Una historia del caminar. Traducción de Álvaro Matus. Madrid: Capitán Swing 
Speranza, Graciela. 2012. Atlas portátil de América Latina: Arte y ficciones errantes. Barcelona: Anagrama

Stramentov, Andrew, Lucia Pietroiusti \& Catherine Bottrill. 2019. "The carbon footprint of contemporary art". Moderator, Chris Hampton. Artworld talk, Art Basel, 12 June. Vídeo de Youtube, 1:05:33. https://www.youtube.com/watch?v=VmL873GBBHo\&feature=youtu.be

\section{Notas}

${ }^{1}$ A partir de este archivo es relativamente sencillo calcular la huella de carbono de un proyecto concreto. Algunos recientes han llegado a las 0.91 toneladas de Co2.

${ }^{2}$ Francis Alÿs. Web personal del artista. https://francisalys.com 